\title{
Author Correction: Androprostamine A: a unique antiprostate cancer agent
}

Yohko Yamazaki - Hikaru Abe - Chiharu Sakashita - Shun-Ichi Ohba - Takumi Watanabe • Isao Momose Manabu Kawada iD

Published online: 18 August 2021

(C) The Author(s), under exclusive licence to the Japan Antibiotics Research Association 2021

Correction to: The Journal of Antibiotics

https://doi.org/10.1038/s41429-021-00449-8

The originally published article contains an error in the depiction of the structure of androprostamine A in Fig. 1.
The correct structure is shown below.<smiles>CC(C)(O)[C@H](NC(=O)C[C@H](N)CCCCNC(=O)CC[C@H](N)C(=O)O)C(=O)N/C(=C\c1cc(O)c(Cl)c(O)c1)C(=O)O</smiles>

The original article has been corrected. 